\title{
Quantifying the magnitude of hazardous incidents among laboratory staff in Kenya; preliminary results of a national health care workers survey, 2014-2015
}

\author{
BK Burmen*, J Osoga
}

From 3rd International Conference on Prevention and Infection Control (ICPIC 2015)

Geneva, Switzerland. 16-19 June 2015

\section{Introduction}

Occupational health surveillance data are vital to effective intervention. Limited information is available on the magnitude of occupational injuries among laboratory personnel in Kenya.

\section{Objectives}

We set out to quantify the prevalence of hazardous injuries among laboratory personnel in Kenya.

\section{Methods}

As part of the Kenya's premier national public health laboratory's training on bio-safety and bio-security, laboratory personnel were invited to take part in a survey on occupational hazards and the safety climate at their workstations. Descriptive statistics were used to summarize types of hazardous incidents experienced by laboratory personnel. Logistic regression was used to describe factors associated with reporting a hazardous injury.

\section{Results}

One hundred and sixteen laboratory personnel drawn from 108 heath facilities participated. Majority were drawn from public health facilities (90\%); the others were from private health facilities $(8 \%)$ and faith based organizations (2\%). Twenty-five (22\%) were from facilities that had reporting mechanisms for occupational exposures. The median duration of service was 4 years (Range 0.2-33.0) and $18(16 \%)$ had ever been trained on bio-safety. Eightynine $(77 \%)$ personnel experienced by 127 incidents, these were: spills (46), sharps injuries (38), hazardous gas inhalation (19), subcutaneous chemical exposures (17), falls (6) and hazardous agents ingestion (1). Incidents occurred during spillage (44\%), laboratory procedures (35\%), waste handling (28\%), surface-contamination (22\%), maintaining equipment (9\%), device use (7\%), while others were due to inappropriate dressing (8\%), food stuff in work area (4\%), fires (2\%) and heavy lifting (1\%). At the time of incident, PPE donned by the majority were gloves $(87 \%)$ and lab coats $(82 \%)$. Only $63 \%$ (56) reported their incidents; sharp injuries were more likely to have been reported (OR 3.1 95\% CI 1.4-7.0, $\mathrm{p}<0.05)$.

\section{Conclusion}

Due to the magnitude of occupational hazards, an integrated information and incident management system should be implemented to routinely document occupational hazards.

\section{Disclosure of interest}

None declared.

Published: 16 June 2015

\section{doi:10.1186/2047-2994-4-S1-P97}

Cite this article as: Burmen and Osoga: Quantifying the magnitude of hazardous incidents among laboratory staff in Kenya; preliminary results of a national health care workers survey, 2014-2015. Antimicrobial Resistance and Infection Control 2015 4(Suppl 1):P97. 